\title{
Verzeichnis der Archive und Bibliotheken
}

Berlin, Geheimes Staatsarchiv, Preußischer Kulturbesitz (GStA PK)

Dresden, Sächsisches Staatsarchiv

Gotha, Forschungsbibliothek (Universitäts- und Forschungsbibliothek Gotha/Erfurt)

Halle, Archiv der Franckeschen Stiftungen (AFSt)

Halle (Saale), Universitäts- und Landesbibliothek

Hamburg, Staats- und Universitätsbibliothek (SUB) Hamburg Carl von Ossietzky

Landesarchiv Sachsen-Anhalt (LASA), Abt. Magdeburg

Kopenhagen, Königliche Bibliothek (Det Kongelige Bibliotek. Danmarks Nationalbibliotek og Københavns Universitetsbibliotek) 
